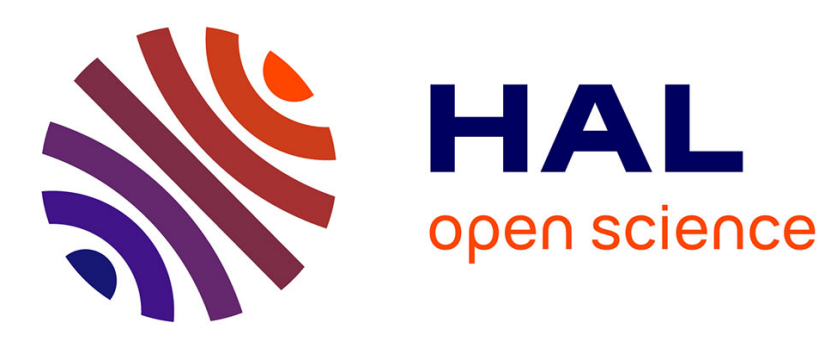

\title{
Surveying Collaborative and Content Management Platforms for Enterprise
}

\author{
Salsabil Dhouib, Riadh Ben Halima
}

\section{To cite this version:}

Salsabil Dhouib, Riadh Ben Halima. Surveying Collaborative and Content Management Platforms for Enterprise. IEEE International Conference on Enabling Technologies: Infrastructures for Collaborative Enterprises ( WETICE ), Jun 2013, Hammamet, Tunisia. 8p. hal-00812686

\section{HAL Id: hal-00812686 https://hal.science/hal-00812686}

Submitted on 12 Apr 2013

HAL is a multi-disciplinary open access archive for the deposit and dissemination of scientific research documents, whether they are published or not. The documents may come from teaching and research institutions in France or abroad, or from public or private research centers.
L'archive ouverte pluridisciplinaire HAL, est destinée au dépôt et à la diffusion de documents scientifiques de niveau recherche, publiés ou non, émanant des établissements d'enseignement et de recherche français ou étrangers, des laboratoires publics ou privés. 


\title{
Surveying Collaborative and Content Management Platforms for Enterprise
}

\author{
Salsabil DHOUIB ${ }^{1} \quad$ Riadh BEN HALIMA ${ }^{1,2,3}$ \\ ${ }^{1}$ University of Sfax, ReDCAD Laboratory, B.P. 1173, Sfax-Tunisia \\ ${ }^{2}$ CNRS, LAAS, 7 avenue du colonel Roche, F-31400 Toulouse, France \\ ${ }^{3}$ Univ de Toulouse, LAAS, F-31400 Toulouse, France \\ dhouib.salsabil@gmail.com, riadh.benhalima@enis.rnu.tn
}

\begin{abstract}
The continuous increasing of the information quantity in enterprises encourages the adoption of an Enterprise Content Management (ECM) that evolves as an integrated approach to information management. By observing the trend toward adoption of Web based collaboration tools in the enterprise, we focus, in this paper, on ECM platforms that involve collaboration and content management aspects in an integrated solution. Thus, to help enterprises that want to move toward a collaborative ECM platform, we provide a detailed analysis of the following ECM platforms: Alfresco, Nuxeo and Microsoft Office SharePoint Server (MOSS). Then, we proceed to the evaluation of Alfresco and MOSS as they are the most used. This allows us to choose the platform that fit most the context of industrial engineering design offices. Therefore, we explored their customization possibilities to meet those offices' organizational requirements. We conclude that MOSS is more appropriate to that context. We carry out experiments on a sandboxed solution on-premises (Microsoft SharePoint 2010) and on Cloud (SharePoint Online) to demonstrate that, on Cloud, we can have a better performance associated to a cheaper cost.

Key words - ECM, MOSS, Alfresco, Nuxeo, Cloud Computing, SharePoint Online, Comparison.
\end{abstract}

\section{INTRODUCTION}

Many enterprises are facing difficulties in information management due to the multiplication of file servers, mail servers, documentary data bases, Web sites and collaborative tools without neither consistency, nor traceability or clear business objectives. The management of such a huge amount of content is a challenge. Enterprises have started to perceive the value of the content in their possession and the importance of handling it efficiently. This is exactly the aim of an Enterprise Content Management (ECM) platform [1].

By following the trend towards cooperation, the gradual navigation of Web 2.0 technologies to the enterprise world and the ever increasing need for collaborative tools and social sharing applied for enterprise content [2][5], we think that the deployment of a collaborative ECM platform is a good choice for enterprises. But, it is difficult to choose the most suitable ECM for an enterprise out of many available solutions. This paper's main aim is to show the strength of each ECM platform, to explore its customization possibilities and to provide a guide in order to choose the suitable one for a specific need.

As a first indicator, we looked at the Gartner magic quadrant [7] and the Forrester wave [6]. We identified the ECM platforms that fit most the business content approach.
Alfresco [8], Nuxeo [9] and MOSS [10] belong to them. Then, we elaborated a comparative study that shows their technical aspects and their business content approach components.

As business content oriented ECM platforms and industrial design engineering offices present a natural synergy, we took a closer look at Alfresco and MOSS. Thus, we explored their customization possibilities in order to meet the organizational requirements of industrial design engineering offices. We concluded that MOSS fits better this context. We then built a sandboxed solution for the project management area that includes a performance assessment. We used Microsoft SharePoint 2010 for the on-premises evaluation and SharePoint Online - the Cloud-based version of Microsoft SharePoint 2010 - for the Cloud evaluation. The obtained result confirms that Cloud gives a cheaper infrastructure and is more competitive.

This paper is structured as follows. In Section 2, we give an overview of the three ECM: Alfresco, Nuxeo and MOSS. Section 3 explores the customization possibilities of Alfresco and MOSS platforms. In Section 4, we evaluate SharePoint Online. We conclude with a summary and suggestions for further research.

\section{ECM PLATFORMS CLASSIFICATION}

ECM is an integrated approach to manage all of enterprise content which can be any datum, document, business application content or multimedia asset related to an organizational business process. According to AIIM [3], an ECM is «the strategies, methods and tools used to capture, manage, store, preserve, and deliver content and documents related to organizational processes. ECM tools and strategies allow the management of an organization's unstructured information, wherever that information exists» [4].

Since the only description available of Alfresco, Nuxeo and MOSS is in the form of natural language marketing whitepapers, we have to study deeply those descriptions in order to identify a set of consistent classification criteria. Given the collaborative aspect of such platforms, we believe that three main criteria make the difference and guide the choice decision: i), the architecture, ii) the evolution capacities, and iii) the performances. The conviviality and the user interface ergonomics are also determining criteria. In addition to technical aspects, fundamental and business content components are also taken in consideration because they are essential to manage effectively the content. A synthesis of the studied technical aspects is presented in TABLE I. 
TABLE I. TeChnicAl Aspects of Alfresco, NuXeO AND Moss

\begin{tabular}{|c|c|c|c|}
\hline \multirow{2}{*}{ Technical Aspects } & \multicolumn{3}{|c|}{ ECM platforms } \\
\hline & Alfresco $3.3>[8][11]$ & Nuxeo 5.5> [9] & MOSS 2007 and Microsoft SharePoint 2010 [10][11] \\
\hline Source code & $\begin{array}{l}\text { - Enterprise version is closed source however } \\
\text { Community version is open source }\end{array}$ & $\begin{array}{l}\text { - It's a real open source model because } \\
\text { code is available for the Enterprise } \\
\text { version }\end{array}$ & - Closed source \\
\hline Price & - Subscription fees for the Enterprise version & - Freeware & - License fees for Microsoft package \\
\hline Sustainability & - Sustainable & - Sustainable & - Very sustainable \\
\hline $\begin{array}{l}\text { Supported } \\
\text { operating systems }\end{array}$ & -Windows, Linux, MacOS, Solaris, etc. & $\begin{array}{l}\text {-Windows Server 2003, Mac OS X, } \\
\text { Unix, Linux, etc. } \\
\text {-Every system on which we can install a } \\
\text { Sun } 1.5 \text { or Sun } 1.6 \text { JVM }\end{array}$ & $\begin{array}{l}\text { - MOSS } 2007 \text { : Windows Server } 2003 \text { (x86 or x64) } \\
\text { or Windows Server } 2008 \text { (x86 or x64) } \\
\text { - Microsoft SharePoint 2010: Windows Server } 2008 \\
\text { x64, Windows } 7 \text { x64 and Vista x64 }\end{array}$ \\
\hline Supported DBMS & - MySQL, MS SQL, Oracle, PostGre SQL, etc. & - PostGre SQL et MySQL & $\begin{array}{l}\text { - MOSS 2007: MS SQL Express or MS SQL } 2005 \\
\text { - Microsoft SharePoint 2010: MS SQL Express or } \\
2005 \text { x64 or } 2008 \text { x64 }\end{array}$ \\
\hline $\begin{array}{l}\text { Supported } \\
\text { application servers }\end{array}$ & $\begin{array}{l}\text { - Tomcat, Jboss, Oracle WebLogic, Oracle } \\
\text { WebSphere, etc. }\end{array}$ & - Jboss, Tomcat & $\begin{array}{l}\text { - The application server role is installed through the } \\
\text { server manager. Thus, the PC is transformed into an } \\
\text { application server }\end{array}$ \\
\hline $\begin{array}{l}\text { API used for the } \\
\text { portal }\end{array}$ & $\begin{array}{l}\text { - Is based on portlets development API Java } \\
\text { Specification Requests (JSR) } 168\end{array}$ & $\begin{array}{l}\text { - Is based on portlets development API } \\
\text { JSR } 168\end{array}$ & - Web Part \\
\hline Other APIs & \begin{tabular}{|l|} 
- JSR 170, Java, JavaScript, Content \\
Management Interoperability Services (CMIS), \\
Simple Object Access Protocol (SOAP), \\
REpresentational State Transfer (REST) \\
\end{tabular} & - JSR 170, Java, CMIS, SOAP, REST & $\begin{array}{l}\text { - MOSS 2007: CMIS, SOAP and Server OM } \\
\text { - Microsoft SharePoint 2010: CMIS, SOAP, Server } \\
\text { OM, Client OM, LINQ and REST }\end{array}$ \\
\hline Protocols & $\begin{array}{l}\text { - FTP, CIFS, WebDAV, NFS, Windows } \\
\text { SharePoint Services (WSS) protocol, IMAP }\end{array}$ & - WebDAV, WSS protocol & - WebDAV \\
\hline $\begin{array}{l}\text { Used technologies } \\
\text { and technical } \\
\text { standards respect }\end{array}$ & $\begin{array}{l}\text { - J2EE platform, Spring Framework } \\
\text { - Uses the best open source technologies } \\
\text { - «Alfresco Explorer» interface is developed } \\
\text { using JSF } \\
\text { - «Alfresco Share» interface is developed using } \\
\text { Spring Surf Framework }\end{array}$ & $\begin{array}{l}\text { - J2EE platform } \\
\text { - Is developed based on existing open } \\
\text { source Frameworks and libraries } \\
\text { - Uses JSF for the presentation layer } \\
\text { - Uses EJB3 }\end{array}$ & - .NET platform, ASP.NET \\
\hline $\begin{array}{l}\text { Software } \\
\text { architecture and } \\
\text { technical platform }\end{array}$ & $\begin{array}{l}\text { - Has a distributed, modular and service } \\
\text { oriented architecture } \\
\text { - Uses Aspect Oriented Programming (AOP) }\end{array}$ & $\begin{array}{l}\text { - Has a modular, components based and } \\
\text { service oriented architecture } \\
\text { - Uses OSGi and a powerful runtime } \\
\text { extension point system } \\
\text { - Is based on Nuxeo EP Framework }\end{array}$ & $\begin{array}{l}\text { - Has a service oriented architecture } \\
\text { - Windows SharePoint Services } 3.0 \text { (WSS v3) is } \\
\text { MOSS 2007's application Framework } \\
\text { - Microsoft SharePoint Foundation } 2010 \text { is } \\
\text { Microsoft SharePoint 2010’s application } \\
\text { Framework }\end{array}$ \\
\hline Usability & $\begin{array}{l}\text { Has two interfaces : } \\
\text { - The old one called «Alfresco Explorer» is } \\
\text { slow, unintuitive, and needs a large number of } \\
\text { clicks for the lesser action } \\
\text { - The new one called «Alfresco Share» is more } \\
\text { clear and adds many functionalities }\end{array}$ & $\begin{array}{l}\text { It's the easiest platform to pick up : } \\
\text { - Clear and intuitive user interface } \\
\text { - A tabbed and very organized interface } \\
\text { - An interface which has interesting } \\
\text { functionalities like the right click } \\
\text { - Rich in AJAX functionalities }\end{array}$ & $\begin{array}{l}\text { - An intuitive and easy to use interface } \\
\text { - Microsoft SharePoint } 2010 \text { uses a ribbon that is } \\
\text { similar to the Microsoft Office one }\end{array}$ \\
\hline $\begin{array}{l}\text { Availability and } \\
\text { load balancing }\end{array}$ & $\begin{array}{l}\text { - Strong availability } \\
\text { - «Alfresco Share»’s availability is stronger } \\
\text { than «Alfresco Explorer» } \\
\text { - Alfresco benefits from a replication } \\
\text { mechanism } \\
\text { - Supports perfectly load balancing }\end{array}$ & $\begin{array}{l}\text { - Strong availability } \\
\text { - It’s possible to establish an application } \\
\text { cluster, and multiply Nuxeo EP instances } \\
\text { that points to a data base }\end{array}$ & $\begin{array}{l}\text { - Strong availability } \\
\text { - Allows high loads: There is no topology by itself, } \\
\text { thus, it’s quite possible to compose any SharePoint } \\
\text { server farm }\end{array}$ \\
\hline $\begin{array}{l}\text { Deployment on- } \\
\text { premises }\end{array}$ & $\begin{array}{l}\text { - Quick deployment: Application comes under } \\
\text { a WAR file. Alfresco comes in Tomcat } \\
\text { application server and MySQL data base } \\
\text { - Configuration after deployment is hard } \\
\text { because we should manually edit a } \\
\text { configuration file }\end{array}$ & $\begin{array}{l}\text { - Quick deployment. Nuxeo comes } \\
\text { packaged, uses a preconfigured turnkey } \\
\text { Tomcat, and is centralized in a unique } \\
\text { folder } \\
\text { - Once application is launched, we } \\
\text { customize settings directly through Web } \\
\text { interface }\end{array}$ & $\begin{array}{l}\text { - Quick deployment } \\
\text { - Once the application is launched, we connect, and } \\
\text { we customize settings directly through the central } \\
\text { administration Web interface }\end{array}$ \\
\hline Cloud support & - Yes (Alfresco) & - Yes (Nuxeo Cloud ECM Edition) & - Yes (SharePoint Online) \\
\hline
\end{tabular}

According to TABLE I, Alfresco and Nuxeo are open source platforms. However, MOSS is a closed source one. MOSS is a Microsoft product which means that it's very sustainable but can only be run on a Windows environment, unlike Alfresco and Nuxeo which can be run on other operating systems. For Alfresco and Nuxeo, we use JSR 168 API to develop portlets, except for MOSS for which we use Web Part. Unlike Nuxeo and MOSS, Alfresco provides CIFS 
option to access repository which is very useful in some enterprise case. Nuxeo and MOSS provide a clear and intuitive user interface. However, Alfresco offers two interfaces called "Alfresco Share», addressed to final users, and «Alfresco Explorer», addressed to administrators. Alfresco is based on the J2EE platform and uses the best open source technologies and AOP. Nuxeo is also based on the J2EE platform. However,
MOSS is based on the .NET platform and uses ASP.NET. We notice that the configuration after deployment is hard for Alfresco, except for Nuxeo and MOSS, where we can customize settings directly through the Web user interface. In addition to technical aspects, fundamental and business content components are also taken into consideration. They are highlighted in TABLE II.

TABLE II. BUSINESS AND FUNDAMENTAL CONTENT COMPONENTS OF ALFRESCO, NUXEO AND MOSS

\begin{tabular}{|c|c|c|c|}
\hline \multirow{2}{*}{\begin{tabular}{|l|} 
Business and \\
fundamental \\
content components
\end{tabular}} & \multicolumn{3}{|c|}{ ECM platforms } \\
\hline & Alfresco $3.3>[8][11]$ & Nuxeo $5.5>[9]$ & MOSS 2007 and Microsoft SharePoint 2010 [10][11] \\
\hline Indexing and search & $\begin{array}{l}\text { - Lucene } \\
\text { - For Alfresco’s } 4.0 \text { version, Lucene has been } \\
\text { replaced by the search engine Solr }\end{array}$ & $\begin{array}{l}\text { - Embedded search engine based on } \\
\text { Lucene }\end{array}$ & $\begin{array}{l}\text { - Has its own indexing and search engine which is } \\
\text { completely independent from SQL Server indexing } \\
\text { service }\end{array}$ \\
\hline $\begin{array}{l}\text { Metadata } \\
\text { management }\end{array}$ & $\begin{array}{l}\text { - Alfresco is based on a content model (types, } \\
\text { properties, constraints, associations, and } \\
\text { aspects) } \\
\text { - Aspects can be attached to documents on the } \\
\text { fly } \\
\text { - Requires XML development }\end{array}$ & $\begin{array}{l}\text { - Through facets } \\
\text { - Requires development }\end{array}$ & $\begin{array}{l}\text { - MOSS is based on a structure called «list». It’s a } \\
\text { highly configurable component that generally } \\
\text { represents a business object. Columns can easily be } \\
\text { added and/or associated to a content type } \\
\text { - It is just a configuration of the standard Web } \\
\text { interface but a content type or a list structure can also } \\
\text { be developed using XML }\end{array}$ \\
\hline Email management & $\begin{array}{l}\text { - Incoming and outgoing email configuration is } \\
\text { manually done. Emails can then be sent when } \\
\text { inviting a user to a space or when a business } \\
\text { rule - including send email action - is executed } \\
\text { A repository node can be configured to receive } \\
\text { emails } \\
\text { - Offers emails drag and drop functionality }\end{array}$ & $\begin{array}{l}\text { - Incoming and outgoing email } \\
\text { configuration is manually done } \\
\text { - Offers a folder type which can be } \\
\text { linked to an inbox }\end{array}$ & $\begin{array}{l}\text { - Incoming and outgoing email configuration is easy } \\
\text { and is done through the central administration Web } \\
\text { interface. SharePoint alerts can then be used, a } \\
\text { document library can be configured to store emails } \\
\text { received from a particular email address } \\
\text { - Offers emails drag and drop functionality }\end{array}$ \\
\hline $\begin{array}{l}\text { Business rules } \\
\text { management }\end{array}$ & $\begin{array}{l}\text { - Integrates a powerful actions orchestration } \\
\text { mechanism } \\
\text { - Has complex business rules that a user can } \\
\text { define without programming (when a document } \\
\text { enter a workspace, do some steps, like } \\
\text { versioning). We have then smart workspaces } \\
\text { - Business rules benefit from AOP technology } \\
\text { which allows changing the server behavior } \\
\text { without changing code. Nevertheless, business } \\
\text { rules can be developed using Alfresco } \\
\text { JavaScript API }\end{array}$ & $\begin{array}{l}\text { - Offers a rules engine that doesn't } \\
\text { emerge on the interface, thus, it's } \\
\text { only a strong tool provided to } \\
\text { developers }\end{array}$ & $\begin{array}{l}\text { - Has an «Event Receiver» module which offers the } \\
\text { possibility to easily add business rules using a simple } \\
\text { development. It includes the business action that will } \\
\text { be triggered when an event occurs. An event receiver } \\
\text { can be attached to a content type which is a powerful } \\
\text { feature } \\
\text { - Has a «Custom Action» module which offers the } \\
\text { possibility to insert buttons and links in MOSS } \\
\text { standard menus. A custom action can be created } \\
\text { without using any line of code. However, in some } \\
\text { cases, it is necessary to write code }\end{array}$ \\
\hline $\begin{array}{l}\text { Business } \\
\text { Intelligence (BI) }\end{array}$ & - Integrates with Jasper Report & $\begin{array}{l}\text { - Has a reporting module by } \\
\text { integrating BIRT solution }\end{array}$ & $\begin{array}{l}\text { - Excel } \\
\text { - PerformancePoint Server integration in MOSS } \\
\text { Enterprise }\end{array}$ \\
\hline $\begin{array}{l}\text { Security and access } \\
\text { rights management }\end{array}$ & $\begin{array}{l}\text { - Supports Single Sign On (SSO) } \\
\text { - Supports any LDAP server } \\
\text { - Manages roles. A role is a set of permissions. } \\
\text { A role can be assigned to users and/or groups } \\
\text { for a document or a workspace through the } \\
\text { invitation mechanism } \\
\text { - Creating a new role requires development }\end{array}$ & $\begin{array}{l}\text { - Supports SSO } \\
\text { - Supports Active Directory and } \\
\text { Open LDAP } \\
\text { - Doesn't include a permissions set } \\
\text { neither as a role like Alfresco nor as } \\
\text { an authorization level like MOSS } \\
\text { - Provides four access rights that can } \\
\text { be applied on workspaces and three } \\
\text { access rights that can be applied on } \\
\text { the metadata of a document }\end{array}$ & $\begin{array}{l}\text { - Supports SSO } \\
\text { - Supports only Active Directory } \\
\text { - Manages authorization levels. An authorization level } \\
\text { is a set of authorizations } \\
\text { - Creating a new authorization level can be simply } \\
\text { done using the standard Web interface } \\
\text { - Security can be applied on site collections, sites, } \\
\text { lists, libraries, list items, and libraries items } \\
\text { - Manages audiences. An audience allows targeting } \\
\text { content items, Web Part components and navigation } \\
\text { links }\end{array}$ \\
\hline $\begin{array}{l}\text { Business Process } \\
\text { Management (BPM) }\end{array}$ & - Uses the jBPM Workflow engine & - Uses the jBPM Workflow engine & $\begin{array}{l}\text { - Workflow functionality is built on Windows } \\
\text { Workflow Foundation }\end{array}$ \\
\hline Collaboration & - Medium & - Medium & - Strong \\
\hline Portal & - Medium & - Strong & - Strong \\
\hline
\end{tabular}

As TABLE II shows, Alfresco is based on an extensible, flexible and evolutionary content model. MOSS is based on a structure called «list» which is the equivalent of an Excel table but provided through a Web interface. It contains columns and items. It's a very powerful tool. Alfresco offers a powerful rules engine. Nuxeo offers also a rules engine but it doesn't emerge in the Web interface. However, MOSS offers two modules called «Custom Action» and «Event Receiver». 


\section{ECM PLATFORMS EVALUATION}

Feature by feature comparison of ECM platforms does not give enough information. We should then develop a practical model. We decided to study the case of industrial engineering design offices. Thus, we installed, set and experimented Alfresco and MOSS. In native mode, they provide the basis features for classic administration and provision team site with tools for collaboration allowing us to focus only on the business part.

We did customizations to meet industrial engineering offices business requirements which consist of being able to reach all the information related to each project, ensuring collaboration between all the project's team members and managing business processes in order to obtain efficiency, reliability and traceability of all operations. Therefore, we explored three areas as follows: Project management, Business Process Management and collaboration.

\section{A. Project management provided technologies}

MOSS is structured into sites. A site constitutes the collaboration environment that can be used in any context, professional as social. We used it in the context of project management. Each site contains lists. A list is the best feature of MOSS. There is no alternative to the list in open source platforms. Every list offers a lot of features. We can connect lists by using a lookup field, which provides a perfect data coherence. We can also create models of a list or a site.

In «Alfresco Share», we find whatever we need in order to perform project management. "Alfresco Share» sites have their dedicated collaborative tools. A site can be considered as a project workspace (Fig. 1). Like MOSS, Alfresco makes possible to define a workspace template.

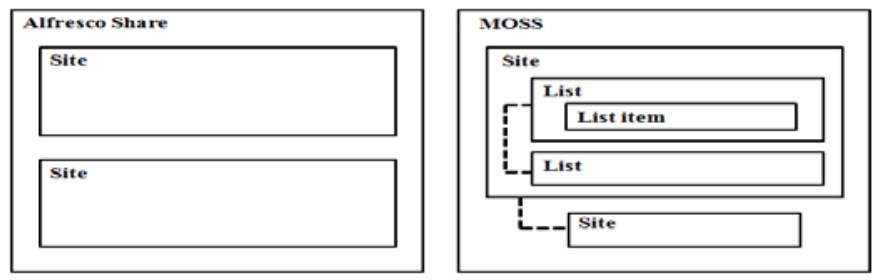

Fig. 1. Structure used for project management in Alfresco and MOSS

\section{B. Business Process Management}

The out-of-the-box Workflows are simple and generic. An industrial engineering office needs to establish complex business Workflows. We implemented a documents approval Workflow using the structure illustrated in Fig. 2.
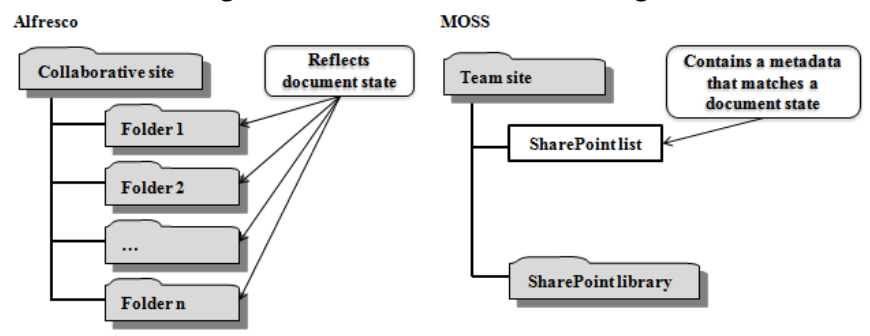

Fig. 2. Structure used to implement the documents approval Workflow
We used jBPM to implement the documents approval Workflow for Alfresco: We installed jPDL Process Designer plugin on Eclipse. We establish business processes with the plugin Graphical Designer environment. We defined the Workflow graph using jBPM Process Definition Language (jPDL), the native Workflow language of jBPM. Then, we called jPDL primitives. We created new interfaces. We found that this is very complicated. In fact, although Alfresco is an open source platform, it's complicated in terms of configuration: an XML file to extend Alfresco's content model, an XML file to describe the Workflow, an XML file responsible for graphical interface displaying, etc.

We used custom actions and event receivers to implement the documents approval Workflow for MOSS. So, we created a SharePoint list on which we implemented a custom action per project user role. When a custom action is selected, a business code is executed and changes are applied on the selected SharePoint list item and its corresponding in the SharePoint document library. It's easier than Alfresco.

\section{Access rights management and collaborative tools}

As Alfresco doesn't allow us to define custom roles via its standard Web interface, we created a Web Script application which enables access rights management by acting on Alfresco repository to assign the required access rights to the appropriate nodes of the collaborative site.

When using MOSS, we can assign authorizations to each team site item via the standard Web interface. We can simply use default authorization levels as well as defining new ones via a simple configuration. Moreover, MOSS contains a very strong tool called «audience». In fact, all navigation links can be targeted for specific audiences via a simple configuration. Thus, we created custom authorization levels. Then, we assigned authorizations to the team site items using two methods: configuration and programming. Also, we developed code to assign access rights to custom actions.

«Alfresco Share» doesn't offer advanced collaborative features and presents many limits. Thus, we decided to couple it with Liferay portal [15]. Liferay will use Alfresco as its documents repository. Then, we tried two solutions. In the first one, we integrated Alfresco Document Library with Liferay. This solution offers a real communication between Alfresco and Liferay. But, it's impossible to search added documents neither via Alfresco nor Liferay and there is a lack of many features. Therefore, we decided to switch to the second solution which consists in the integration of Alfresco DocLib portlet in Liferay. Using this solution, we can access to all "Alfresco Share» sites, benefit from the great power of «Document Library» and avoid coding. However, it's impossible to add sites through Liferay. The only way is to access to Alfresco in order to create a new site. In conclusion, it's clear that there is a general problem of Alfresco and Liferay versions compatibility. In addition, we note that there is a communication but not an integration. Indeed, to integrate Alfresco with Liferay, we must use Alfresco’s SOAP API and integrate Web services in portlets applications deployable in Liferay. However, MOSS offers appetizing collaborative 
features. Thus, we don't need to perform modifications at this level.

\section{Synthesis}

In one hand, Alfresco extensibility is quite difficult in terms of programming. It presents a lack of flexibility at deployment level and requires apprenticeship and a mastering of its implementation. On the other hand, Alfresco presents a powerful rules engine, offers the possibility to add aspects on the fly, and doesn't require a Client Access License (CAL). It is privileged if the project simply uses the offered standard function. MOSS is simple in its forms and Workflows management. It is only a $20 \%$ of code and $80 \%$ of declarative logic (no code) and settings associated to the platform. We conclude that Alfresco remains an interesting solution. However, MOSS seems to be the best fit with our issues, but it is a closed source solution and requires a lot of licenses.

\section{SHAREPOINT ONLINE ASSESSMENT}

The deployment cost of a small Microsoft SharePoint 2010 farm on-premises is high [13]. Nevertheless, Microsoft hosts a version of Microsoft SharePoint 2010 product in its own Data Centers. According to NIST [16], «Cloud Computing is a model for enabling ubiquitous, convenient, on-demand network access to a shared pool of configurable computing resources (e.g., networks, servers, storage, applications, and services) that can be rapidly provisioned and released with minimal management effort or service provider interaction. This Cloud model is composed of five essential characteristics, three service models, and four deployment models» [17].

\section{A. Microsoft Office 365}

Microsoft Office 365 [14] is the Microsoft Cloud SaaS offer. It comes after and replaces Business Productivity Online Suite (BPOS). It's a service in the form of User Subscription License (USL). It addresses all enterprises regardless of size for collaboration and communication services hosted on Cloud. It includes Office Professional Plus, Exchange Online, SharePoint Online and Lync Online.

Two families of offers are available, Office 365 for Professionals and Small Businesses $« \mathrm{P} »$ (contains one package called «P1») and Office 365 for Medium and Large Businesses «E» (contains four packages called «E1», «E2», «E3» and «E4»). Those two families of offers include many services which are completely appropriate for the enterprise structure, its number of employees and its equipment. There are two different versions of Office 365: The standard one which is held in reserve for small and medium-sized enterprises and is based on a multi-tenant architecture; and the dedicated version, which is held in reserve for large-sized enterprises and is based on a multi-instance architecture.

\section{B. SharePoint Online customization}

We can upload custom code to SharePoint Online with the use of the Client Object Model and the new sandboxed solution feature inherited from Microsoft SharePoint 2010 [14]:

- Client Object Model: It's a new feature of Microsoft SharePoint 2010. It provides features to program against a SharePoint site using .NET Managed Code or JavaScript. It provides almost the programming features of the Server Object Model plus advantages in deployment.

- Sandboxed solutions: They are run using a restrictive set of code access security policies and are limited to a specific subset of the Server Object Model. They are also monitored. Among the components that can be deployed, we can find: Web Parts, Event Receivers, Feature Receivers, etc. The process of deploying such a solution on SharePoint Online is illustrated in Fig. 3.

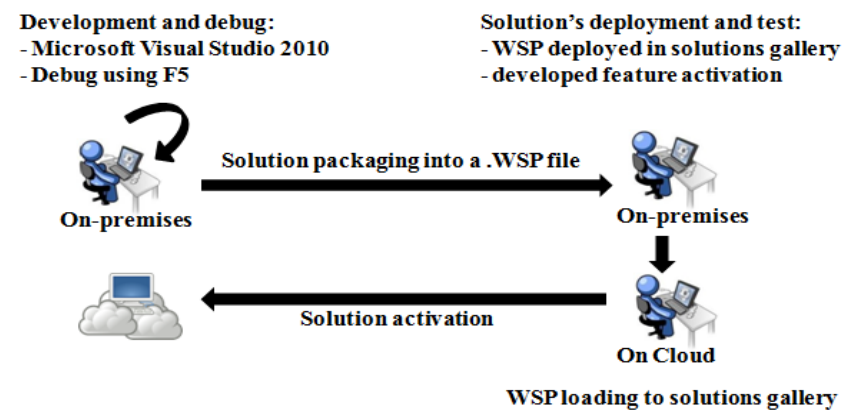

Fig. 3. The process of deploying a sandboxed solution on SharePoint Online

\section{Experimental study}

To validate our orientation toward Cloud [18], we developed a sandboxed solution based on an event receiver. This solution contains a mechanism allowing automation of documents creation process thereby providing and ensuring data consistency. In order to perform this, we created a SharePoint list which contains the project items metadata, and a SharePoint document library which contains the project documents grouped by disciplines. The Event Receiver is triggered when a new item is added to the list, in order to automatically create a folder (if necessary) and a file in the document library. To measure the response time relative to the treatment being executed in the event receiver, we used the technique of the timer inserted in the code [12].

For the on-premises development, we used a machine having the following software and hardware configuration: A processor: Intel ${ }^{\circledR}$ Core ${ }^{\mathrm{TM}} 2$ Duo Processor P7350, a RAM: 4 Go, a hard disk: 100 Go, an OS: Windows Server 2008 R2 and the IDE Microsoft Visual Studio 2010. We did 390 requests and we measured, in each one, the response time. For SharePoint Online, we decided to evaluate Standard Office 365 P1 and E3 plans because they offer 30-day free trial. We created the same SharePoint components and defined the same data structure, we used the same sandboxed solution and the same test machine. Then, we activated the feature, used in the sandboxed solution, on SharePoint Online. We used the same requests number and we measured the response time. We classified results into intervals of 26 requests and we mentioned the minimal and the maximal response time value obtained in each interval as shown in TABLE III. In order to have a better results exploitation, we dressed the response time measurement curves for the three case studies as illustrated in Fig. 4. 
TABLE III. RESPONSE TIME EVOLUTION ON-PREMISES AND ON CLOUD

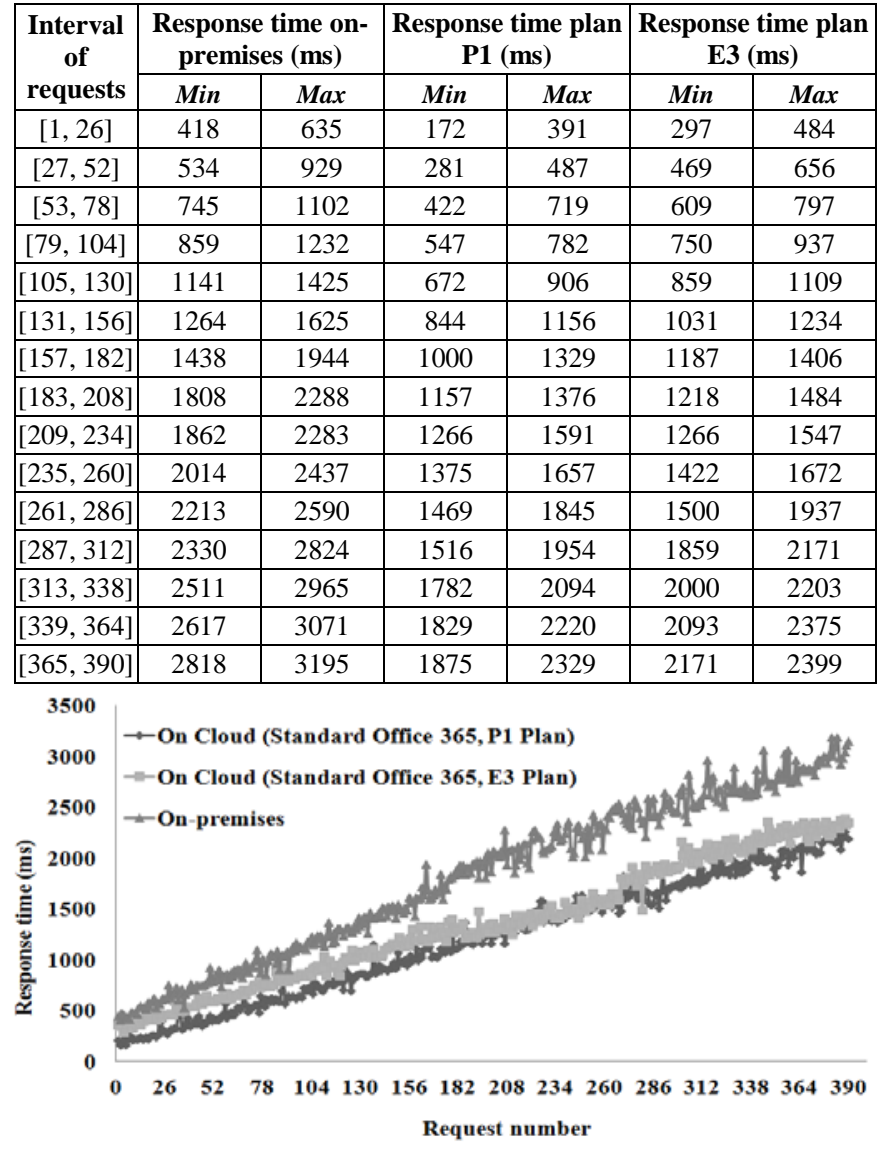

Fig. 4. Response time evolution on-premises versus on Cloud

As it's shown in Fig. 4, when the number of tests increases, response time increases too. In addition, the response times of the plans P1 and E3 are similar. It's clear that the execution of the sandboxed solution on Cloud is more efficient than its execution on-premises. With a number of request less than 100 , there is a little difference in response time between onpremises and on Cloud. However, with a high number of requests, the difference is becoming significantly important.

\section{CONCLUSION AND FUTURE WORK}

In this paper, we elaborated a comparative study of three ECM platforms called Alfresco, Nuxeo and MOSS, showing their technical aspects and their business content approach components. Afterward, we explored, evaluated, and customized Alfresco and MOSS in the context of industrial engineering design offices. At Alfresco level, we developed a Web Script application to manage access rights, created a business Workflow and integrated Alfresco with Liferay portal. At MOSS level, we developed a business Workflow. Then, we evaluated the performance of MOSS on-premises and on Cloud. For this purpose, we applied the process of deploying a sandboxed solution on SharePoint Online. We showed that in Cloud, we have a better performance. Our short-time goal is to include other ECM platforms in our comparative study. In the long term, we intend to draw up dashboards for ECM platforms in order to offer a global vision of the application's functional part progress as well as the monitoring part.

\section{REFERENCES}

[1] Tim A. Rickenberg, Markus Neumann, Bernd Hohler and Michael Breitner, "Enterprise Content Management - A Literature Review," in Proceedings of the 18th Americas Conference on Information Systems (AMCIS), Seattle, Washington, 2012. AISeL.

[2] Ginika C. Onyechi and Geetha Abeysinghe, "Adoption of Web Based Collaboration Tools in the Enterprise: Challenges and Opportunities," in Proceedings of the International Conference on the Current Trends in Information Technology (CTIT), Dubai, UAE, 2009, pp. 1-6. IEEE.

[3] AIIM. http://www.aiim.org/.

[4] AIIM. "What is Enterprise Content Management," [Online]. Available: http://www.aiim.org/What-is-ECM-EnterpriseContent-Management [Accessed: Sep. 12, 2011].

[5] Muhammad Usman, Abdul Wahab Muzaffar and Abdul Rauf, "Enterprise Content Management (ECM): Needs, Challenges and Recommendations," in Proceedings of the $2^{\text {nd }}$ IEEE International Conference on Computer Science and Information Technology (ICCSIT), Beijing, 2009, pp. 283-289. IEEE.

[6] Alan Weintraub. The Forrester Wave ${ }^{\mathrm{TM}}$ : Enterprise Content Management, Q4 2011. November 2011.

[7] Mark R. Gilbert, Karen M. Shegda, Kenneth Chin, Gavin Tay and Hanns Koehler-Kruener (2012, Oct. 18). "Magic Quadrant for Enterprise Content Management," [Online]. Available: http://www.project-consult.de/files/Oracle_Gartner-MagicQuadrant-ECM_20121018.pdf [Accessed: Nov. 18, 2012].

[8] Alfresco. http://www.alfresco.com/.

[9] Nuxeo. http://www.nuxeo.com/.

[10] MOSS. http://www.microsoft.com/SharePoint/.

[11] Thomas Büchner, Florian Matthes and Christian Neubert, "Functional Analysis of Enterprise 2.0 Tools: A Services Catalog," in Lecture Notes of Communications in Computer and Information Science (CCIS), 2010, pp. 351-363. Springer.

[12] Florian Rosenberg, Christian Platzer and Schahram Dustdar, "Bootstrapping performance and dependability attributes of web services," in Proceedings of the IEEE International Conference on Web Services (ICWS'06), Washington, DC, USA, 2006, pp. 205-212. IEEE.

[13] Joel C. "SharePoint 2010 Pricing Explained". Oct. 1, 2012. [Blog entry]. Available: http://www.pinnacleofindiana.com/ blog/post/2012/10/01/sharepoint-2010-pricing-explained.aspx [Accessed: Jan. 10, 2012].

[14] Philip Wicklund, Microsoft SharePoint 2010: Deploying Cloud based Solutions, Oct. 2011.

[15] Liferay. http://www.liferay.com/.

[16] NIST. http://www.nist.gov/.

[17] Peter Mell and Timothy Grance (2011, Sep.). "The NIST Definition of Cloud Computing," [Online]. Available: http://csrc.nist.gov/publications/nistpubs/800-145/SP800145.pdf [Accessed: Nov. 18, 2011].

[18] David Banks, Jhon S. Erickson and Michael Rhodes, "Toward Cloud-based Collaboration Services," in Proceedings of the $1^{\text {st }}$ conference on Hot topics in cloud computing, San Diego, CA, USA, 2009. ACM. 